\title{
The 6 domains of behavior change: the missing health system building block
}

Behavior is crucial throughout global health interventions. The discipline of behavior change offers distinct expertise needed across 6 different domains of behavior. Such expertise is in short supply, however. We will not have effective and sustainable health systems, nor achieve our ambitious global health goals, without seriously addressing behavior change.

T he 2010 Global Burden of Disease (GBD) report makes strikingly clear the absolutely critical role of behavior to health. Despite the limitations of the GBD, it is remarkable that, for sub-Saharan Africa, for example, 15 of the top 20 health risk factors are predominantly behavioral, and the other 5 are highly influenced by behavior (Table). ${ }^{1}$

When we think about behavior, we tend to focus on predisposing individual, or "lifestyle," behaviors with a strong relationship to health and disease. But behavior is crucial throughout health interventions. Indeed, the importance of behavior so permeates all of global health efforts-both preventive and curativethat interventions to influence behavior constitute an overlooked building block in health systems.

Below, I outline 6 domains of behavior and how each is important to our efforts to improve health. Although these domains often overlap, it is useful to consider each domain in turn because they are, to some extent, distinctive. And the principles and skill set of the behavior change discipline can be applied across them.

1. Freestanding, personal or lifestyle behaviors. These behaviors, such as those contributing to the risk factors listed in the Table, are behaviors that people can modify on their own, without the involvement of the clinical health system, to improve health or forestall illness. Examples in traditional global health priorities include: exclusive breastfeeding, hand washing, oral rehydration, wearing shoes to prevent helminth infection, and safe sexual practices. But free-standing behavior is also, or, arguably, even more, crucial to prevent noncommunicable disease and injury (NCDI)-behaviors such as tobacco and alcohol avoidance; use of seatbelts, motorcycle helmets, and clean-burning cook stoves; and adequate physical activity. Both over- and undernutrition affect the traditional and NCDI health priorities in numerous profound ways.

2. Care-seeking behavior or demand. Clearly, illness often drives people to seek care, but not always. Or, they seek it too late or from the wrong provider. Examples of crucial care-seeking include:

- Timely access to more skilled delivery services, when complications occur during labor ${ }^{2}$

- Early treatment of tuberculosis (TB), where it is estimated that the typical person with active TB infects 3 to 6 others $^{3}$

- Male circumcision for HIV prevention, which has not been readily accepted by older men, who are by far the highest-risk age group and epidemiologically critical $^{4}$

- HIV counseling and testing, where, unfortunately, many people at risk still forego testing ${ }^{5}$

- HIV treatment, where many turn to faith healing in search of cure ${ }^{6}$

- Family planning, where unmet need remains high in many countries ${ }^{7}$

- Immunization, where "vaccine hesitancy" among parents is a major impediment ${ }^{8}$

- Treatment of pneumonia and sepsis, especially in the early neonatal period, where recognition of early signs and quick treatment are essential ${ }^{9}$

3. Client adherence and collaboration. Once a therapy or other intervention is undertaken, the client's adherence or collaboration can be pivotal. After all, in TB treatment DOTS (Directly Observed Therapy - Short Course) was developed to assure adequate drug adherence. In family planning, discontinuation, especially of oral contraceptives and injectables, is a major reason for unintended 
TABLE. Global Burden of Disease 2010: Top 20 Risk Factors, Sub-Saharan Africa

\begin{tabular}{|c|c|c|c|}
\hline Rank & Risk Factor & $\begin{array}{c}\text { Predominantly } \\
\text { Behavioral }\end{array}$ & $\begin{array}{l}\text { Strong Behavioral } \\
\text { Contribution }\end{array}$ \\
\hline 1 & Alcohol & $x$ & \\
\hline 2 & High blood pressure & & $x$ \\
\hline 3 & Obesity & $x$ & \\
\hline 4 & Suboptimal breastfeeding & $x$ & \\
\hline 5 & Tobacco & $x$ & \\
\hline 6 & High blood glucose & & $x$ \\
\hline 7 & Household air pollution & $x$ & \\
\hline 8 & Diet low in fruits & $\mathrm{x}$ & \\
\hline 9 & Childhood underweight & $x$ & \\
\hline 10 & Iron deficiency & $x$ & \\
\hline 11 & Physical inactivity & $x$ & \\
\hline 12 & Drug use & $x$ & \\
\hline 13 & Diet high in sodium & $x$ & \\
\hline 14 & Intimate partner violence & $x$ & \\
\hline 15 & Diet low in vegetables & $x$ & \\
\hline 16 & Diet low in nuts and seeds & $x$ & \\
\hline 17 & Vitamin A deficiency & $\mathrm{x}$ & \\
\hline 18 & Unimproved sanitation & & $x$ \\
\hline 19 & High total cholesterol & & $x$ \\
\hline 20 & Lead exposure & & $x$ \\
\hline
\end{tabular}

pregnancies. In HIV prevention, failure to use condoms correctly and consistently allows infection, while in HIV treatment discontinuation of antiretroviral (ARV) drugs leads to mortality. In malaria prevention, the success of bed nets depends on people, especially the most vulnerable, sleeping under them. Helmets protect only the cyclists who wear them. And clinical approaches to hypertension and diabetes depend greatly on adherence, often to more than one drug. Moreover, poor adherence to antimicrobials leads to drug resistance, which undermines efforts for the entire population.

4. Provider behavior. Providers are people, too. We expect them to be competent, caring, and hardworking, but they have values, motivations, misconceptions, capabilities, constraints, social norms, and other priorities like anyone else. What they do and don't do can absolutely make or break many health programs. For example, poor provider performance in IMCI (Integrated Management of Childhood Illness) stems from a variety of behavioral factors including providers' beliefs and misunderstandings, cultural factors, profit motives, negligence, and forgetfulness. ${ }^{10}$ In malaria care, providers' propensity to treat any fever as malaria is dysfunctional. ${ }^{11}$ Many providers continue to treat non-bloody diarrhea with inappropriate antibiotics. ${ }^{12}$ In family planning, many providers avoid IUDs, 
partly because they lack confidence in their skills and inserting IUDs is time-consuming. ${ }^{13}$ Providers also manage their workloads partly by regulating who and how many clients they see. ${ }^{13}$ And clinicians in general are ill-prepared and ill-disposed to most counseling, despite counseling's often pivotal role.

5. Pro-social and anti-social behavior. These are behaviors that influence the health of the community or society at large. They include a wide variety of positive behaviors, such as covering one's mouth when coughing, using latrines, vaccinating one's chickens against avian influenza, and installing traffic-calming devices such as speed bumps, but also negative ones, such as reckless driving, generating air pollution, and even terrorism. These behaviors could be grouped with the first category, the freestanding ones, but typically they require different appeals, transcending appeals to self-interest.

6. Policy and priority setting. The behavior of policy makers clearly has a profound influence, notably on funding levels. But programmatic policies are important, too, driving what interventions are prioritized, how they are delivered, the way work is organized, who does what, what gets measured, and what gets rewarded. To some extent, policy is influenced by the medical culture of physicians and other health professionals, who typically manage and influence health programming. A common resulting problem is the preference for curative and clinical services over key prevention interventions. Another is resistance to task shifting, such as provision of simple but vital drugs and contraceptives by community health workers. Similarly, public attitudes are important. Clearly, general concern about HIV has helped galvanize the effective response. In contrast, fatalism and acceptance of maternal mortality as a "normal" occurrence has impeded maternal health initiatives. ${ }^{14}$

\section{APPLYING COMMON PRINCIPLES OF BEHAVIOR CHANGE ACROSS THE DOMAINS}

Why is appreciating these domains important? First, success in many global health priorities requires addressing multiple domains collectively. For example, good "combination" prevention in HIV calls for reducing sexual risk-taking and correct use of condoms (domains 1, 3, and 5), initiation and adherence to ARV drugs (since ARVs inhibit transmission) (domains 2 and 3), good counseling to support these behaviors among clients (domain 4), building demand for male circumcision and HIV testing (domain 2), and adequate funding and enlightened policies such as task shifting to support all of it (domain 6 ). In this issue of GHSP, Kamhawi et al. address 3 domains-promoting client demand (2), improving provider counseling (4), and supporting continued successful use (3)-in their intervention to improve use of family planning. ${ }^{15}$

At the same time, although each domain has its own characteristics, behavior change is a distinct discipline with its own approaches and skill sets that apply across the domains. Briefly, its components include:

- Understanding thoroughly the intended audiences, often through formative research

- Tailoring approaches to those audiences

- Using multiple vehicles of messaging and learning

- Appealing effectively to both heart and mind

- Promoting sustained behavior change, including building health literacy and positive habits

- Addressing key family members and communities and the social norms that they help to establish

- Including structural approaches that support positive behavior (for example, tobacco tax,

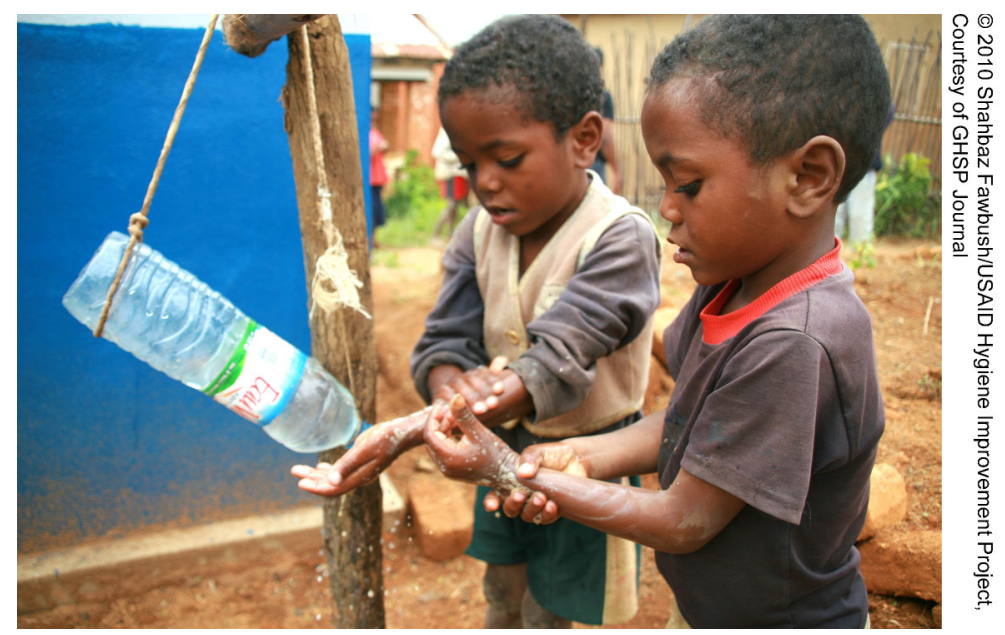

Two boys in Madagascar use soap and a water-saving "tippy tap" to wash their hands. 
phone text medication reminders, and performance checklists for providers)

- Addressing incentives

- Measuring impact and making adjustments on a continuing basis

We can apply this behavioral expertise across all 6 domains and promote synergy. But behavioral expertise is in precious short supply, especially in developing countries. We need to expand and strengthen that expertise in institutions and to foster competent behavior specialists, but also to increase the behavioral expertise of all health cadres.

Any health system worth its salt must address the missing building block of behavior change in a vigorous way. We cannot achieve our ambitious global health goals without it. - James D. Shelton, Editor-in-Chief

\section{REFERENCES}

1. Lim SS, Vos T, Flaxman AD, Danaei G, Shibuya K, Adair-Rohani $\mathrm{H}$, et al. A comparative risk assessment of burden of disease and injury attributable to 67 risk factors and risk factor clusters in 21 regions, 1990-2010: a systematic analysis for the Global Burden of Disease Study 2010. Lancet. 2012;380(9859):22242260. CrossRef. Medline

2. Thaddeus $S$, Maine D. Too far to walk: maternal mortality in context. Soc Sci Med. 1994;38(8):1091-1110. CrossRef. Medline

3. van Leth F, van der Werf MJ, Borgdorff MW. Prevalence of tuberculous infection and incidence of tuberculosis; a reassessment of the Styblo rule. Bull World Health Organ. 2008;86(1):20-26. CrossRef. Medline

4. Plotkin M, Castor D, Mziray H, Küver J, Mpuya E, Luvanda PJ, et al. "Man, what took you so long?" Social and individual factors affecting adult attendance at voluntary medical male circumcision services in Tanzania. Glob Health Sci Pract. 2013;1(1):108-116. CrossRef
5. Cawley C, Wringe A, Isingo R, Mtenga B, Clark B, Marston M, et al. Low rates of repeat HIV testing despite increased availability of antiretroviral therapy in rural Tanzania: findings from 2003-2010. PLoS One. 2013;8(4):e62212. CrossRef. Medline

6. Musheke M, Bond V, Merten S. Deterrents to HIV-patient initiation of antiretroviral therapy in urban Lusaka, Zambia: a qualitative study. AIDS Patient Care STDS. 2013;27(4):231241. CrossRef. Medline

7. Van Lith LM, Yahner M, Bakamiian L. Women's growing desire to limit births in sub-Saharan Africa: meeting the challenge. Glob Health Sci Pract. 2013;1(1):97-107. CrossRef

8. Schwartz JL, Caplan AL. Vaccination refusal: ethics, individual rights, and the common good. Prim Care. $2011 ; 38(4): 717-728$, ix. CrossRef. Medline

9. Zaidi AK, Ganatra HA, Syed S, Cousens S, Lee AC, Black R, et al. Effect of case management on neonatal mortality due to sepsis and pneumonia. BMC Public Health. 2011;11 Suppl 3:S13. CrossRef. Medline

10. Rowe AK, Onikpo F, Lama M, Cokou F, Deming MS. Management of childhood illness at health facilities in Benin: problems and their causes. Am J Public Health. 2001;91(10):1625-1635. CrossRef. Medline

11. Reyburn H, Mbatia R, Drakeley C, Carneiro I, Mwakasungula E, Mwerinde $\mathrm{O}$, et al. Overdiagnosis of malaria in patients with severe febrile illness in Tanzania: a prospective study. BMJ. 2004;329(7476):1212. CrossRef. Medline

12. Gwimile JJ, Shekalaghe SA, Kapanda GN, Kisanga ER. Antibiotic prescribing practice in management of cough and/or diarrhoea in Moshi Municipality, Northern Tanzania: crosssectional descriptive study. Pan Afr Med J. 2012;12:103. Available from: http://www. panafrican-med-journal.com/ content/article/12/103/full/. Medline

13. Shelton JD. The provider perspective: human after all. Int Fam Plann Persp. 2001;27(3):152-161. Available from: http:// www.guttmacher.org/pubs/journals/2715201.html

14. D'Ambruoso L, Byass P, Qomariyah SN. 'Maybe it was her fate and maybe she ran out of blood': final caregivers' perspectives on access to care in obstetric emergencies in rural Indonesia. J Biosoc Sci. 2010;42(2):213-241. CrossRef. Medline

15. Kamhawi S, Underwood C, Murad H, Jabre B. Client-centered counseling improves client satisfaction with family planning visits: evidence from Irbid, Jordan. Glob Health Sci Pract. 2013;1(2):180-192. CrossRef

First Published Online: 2013 Aug 14

Cite this article as: Shelton JD. The 6 domains of behavior change: the missing health system building block. Glob Health Sci Pract. 2013;1(2):137140. http://dx.doi.org/10.9745/GHSP-D-13-00083.

(c) Shelton JD. This is an open-access article distributed under the terms of the Creative Commons Attribution License, which permits unrestricted use, distribution, and reproduction in any medium, provided the original author and source are properly cited. To view a copy of the license, visit http://creativecommons.org/licenses/by/3.0/ 